\title{
Global climate change - a feasibility perspective of its effect on human health at a local scale
}

\author{
Michele Bernardi \\ Climate Change and Bioenergy Unit, Food and Agriculture Organization of the United Nations (FAO), \\ Rome, Italy
}

\begin{abstract}
There are two responses to global climate change. First, mitigation, which actions to reduce greenhouse gas emissions and sequester or store carbon in the short-term, and make development choices that will lead to low emissions in the long-term. Second, adaptation, which involves adjustments in natural or human systems and behaviours that reduce the risks posed by climate change to people's lives and livelihoods. While the two are conceptually distinct, in practice they are very much interdependent, and both are equally urgent from a healthy population perspective. To define the policies to mitigate and to adapt to global climate change, data and information at all scales are the basic requirement for both developed and developing countries. However, as compared to mitigation, adaptation is an immediate concern for low-income countries and for small islands states, where the reduction of the emissions from greenhouse gases is not among their priorities. Adaptation is also highly location specific and the required ground data to assess the impacts of climate change on human health are not available. Climate data at high spatial resolution can be derived by various downscaling methods using historical and real-time meteorological observations but, particularly in low-income countries, the outputs are limited by the lack of ground data at the local level. In many of these countries, a negative trend in the number of meteorological stations as compared as to before 2000 is evident, while remotelysensed imagery becomes more and more available at high spatial and temporal resolution. The final consequence is that climate change policy options in the developing world are greatly jeopardized.
\end{abstract}

Keywords: climate change, climate variability, global warming, human health, meteorological observations, remote sensing.

Before starting to discuss influence and interaction involving the climate, it is essential to define what we mean by environment and health. The former can be defined as the complex of physical, chemical, and biological factors in which a living organism or community exists. In simple terms, the environment refers to the components of the Earth and includes, but is not limited to: (i) land, water and air, including all layers of the atmosphere; (ii) organic and inorganic matter and living organisms;

Corresponding author:

Michele Bernardi

Climate Change and Bioenergy Unit (NRCB)

Environment, Climate Change and Bioenergy Division

Natural Resources Management and Environment Department

Food and Agriculture Organization of the United Nations (FAO)

Viale delle Terme di Caracalla, 00153 Rome, Italy

Tel. +3906 57052 442; Fax +3906570 53369

E-mail: Michele.Bernardi@fao.org and (iii) the interaction among and between the components referred to (i) and (ii). In 1948, in its constitution, the World Health Organization (WHO) defined health as follows: "Health is a state of complete physical, mental and social well-being and not merely the absence of disease or infirmity" (WHO, 2006).

The interaction between environment and health is well-known since Hippocrates, the father of medicine (460-377? B.C.), who was the first we know of taking a scientific approach towards diseases and cures. He taught that proper diet is a necessity of health, and that the climate has a profound influence on both mind and body. In his writings Hippocrates says: "Whoever would study medicine aright must learn of the following subjects. First he must consider the effect of each of the seasons of the year and the differences between them. Secondly he 
must study the warm and the cold winds, both those which are common to every country and those peculiar to a particular locality...... Lastly, the effect of water on health must not be forgotten. Just as it varies in taste and when weighed, so does its effect on the body vary as well. When, therefore, a physician comes to a district previously unknown to him, he should consider both its situation and its aspects to the winds. The effect of any town upon the health of its population varies according as it faces north or south, east or west. This is of the greatest importance" (Airs, Waters, Places, 400 B.C.).

Due to the link between the environment and human health, a healthy population is dependent on a healthy environment and, also, the environment can be affected by human activities. Any major change in climatic conditions is likely to have consequences for human population health. On the other hand, the most recent global climate assessment states that the net effect of human activities since 1750 has been, with a very high confidence 1 , a determinant of the increased global temperatures (IPCC, 2007a).

\section{The "climate dimension"}

While the climate, in a narrow sense, can be defined as the "average weather", the more rigorous statistical description sees it in terms of the mean and variability of relevant quantities over a period of time ranging from months to thousands or millions of years. The classical period is 30 years, as defined by the World Meteorological Organization (WMO). These relevant quantities are most often surface variables such as temperature, precipitation, and wind. Climate in a wider sense is the state including a statistical description, of the climate system.

The climate system is a complex system which, under the effects of the solar radiation received by

\footnotetext{
1 Degree of confidence in being correct: very high confidence: at least 9 out of 10 chance of being correct; high confidence: about 8 out of 10 chance; medium confidence: about 5 out of 10 chance; low confidence: about 2 out of 10 chance; and very low confidence: less than 1 out of 10 chance.
}

Earth, determines our climate and it consists of five major components (Fig. 1) and the interactions between them. The climate system evolves in time under the influence of its own internal dynamics and external forces such as volcanic eruptions, solar variations and anthropogenic forces such as the changing composition of the atmosphere and landuse change (IPCC, 2007a). As shown in Figure 1, the five components of the climate system are:

(i) the atmosphere (gaseous matter above the surface of the Earth);

(ii) the hydrosphere (liquid water on or below the surface of the Earth);

(iii) the cryosphere (snow and ice on or below the surface of the Earth);

(iv) the lithosphere (land surface of the Earth, e.g. rock, soil and sediment); and

(v) the biosphere (plants and animal life, including man).

\section{Climate classification}

The interaction of the systems produces different climates on the Earth which can be described at different scales and the global climate is assessed by, basically, measuring the global average temperature of Earth's surface through the analysis of thousands of records of temperature collected from meteorological stations on land and at sea. Although the climate per se relates only to the varying states of the atmosphere, the other parts of the climate system also have a significant role in forming different climates through their interactions with the atmosphere (Fig. 2 ). In considering the interactions of the various components of the climate system it is clear that they have a vertical influence as well as a horizontal one. To understand those interactions, it is important to define a climatic scale which links the macro, the meso, the local and the micro climates (Fig. 3), but also to link the climatic scale with the meteorological scale as the climatic phenomena represent the cumulative effect of the meteorological phenomena.

The climate can be classified according to different rules but, in general, it can be divided into a 


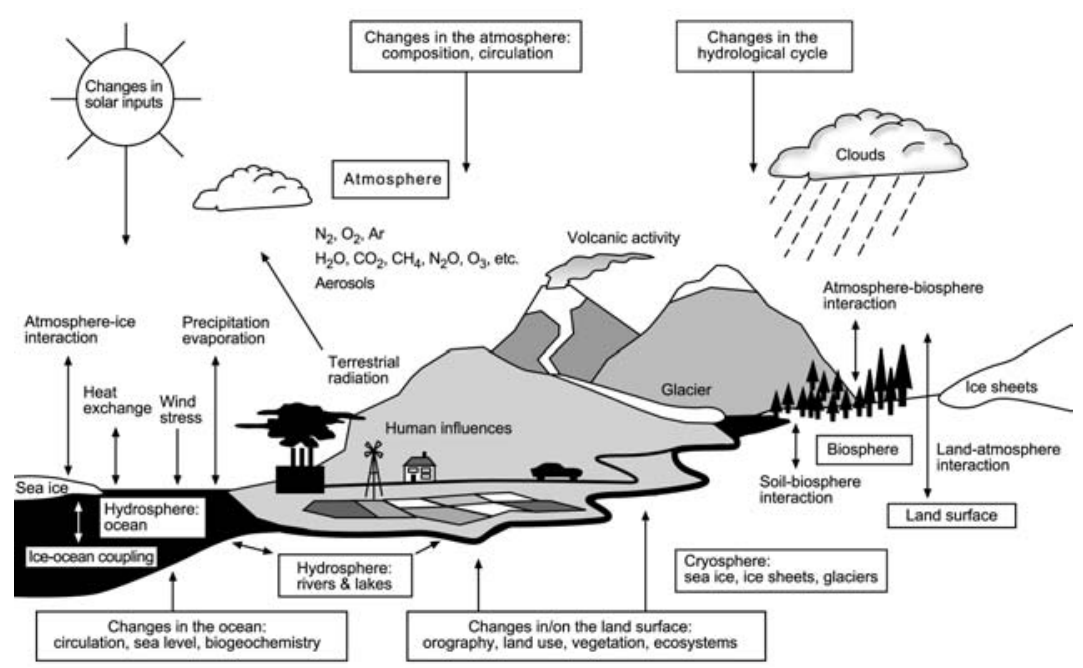

Fig. 1. The climate system (source: IPCC, 2001a).

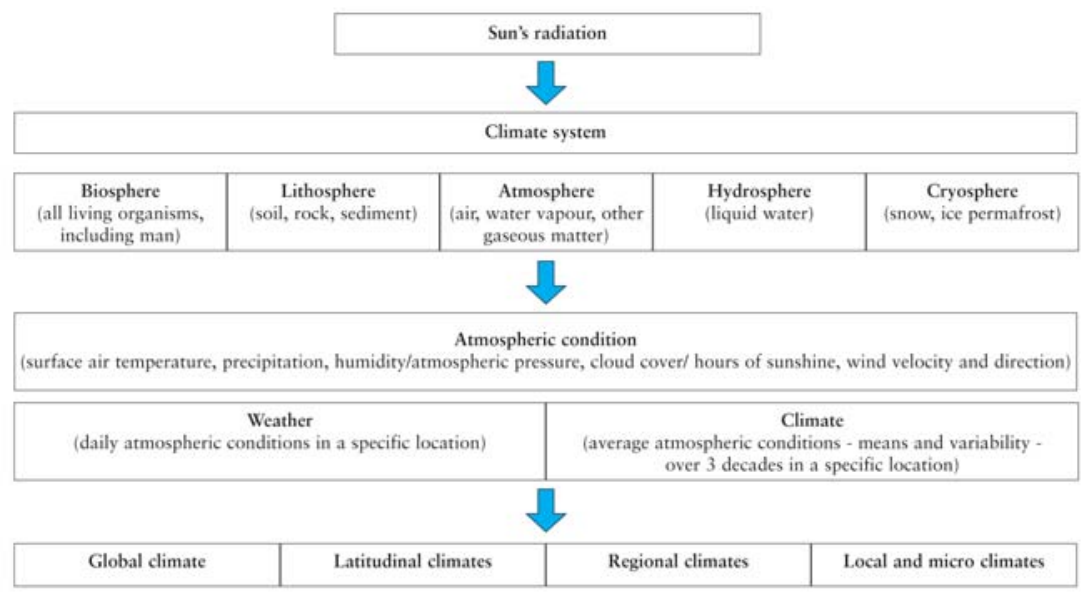

Fig. 2. The pathway from the Sun's radiation to the formation of climates (source: FAO, 2007).

worldwide system of contiguous regions, each of which is defined by the relative homogeneity of its climatic elements. One of the first attempts to do so was done by Aristotle in ancient Greece (284-322 B.C.). Aristotele hypothesized that the Earth was divided into three types of climatic zones, each based on distance from the equator:

(i) Torrid Zones - from the Tropic of Cancer $\left(23.5^{\circ}\right)$ in the north, through the equator $\left(0^{\circ}\right)$, to the Tropic of Capricorn $\left(23.5^{\circ}\right)$ in the south;

(ii) Frigid Zones - north of the Arctic Circle $\left(66.5^{\circ}\right.$ north) and south of the Antarctic Circle $\left(66.5^{\circ}\right.$ south); and

(iii) Temperate Zones - between the Tropics and the Arctic and Antarctic Circles.

The currently most effective classification scheme is that of Wladimir Köppen (1936) that is based on the characteristics of the mean annual cycle of temperature and precipitation. Threshold values utilizing these climatic parameters were defined in order to designate climate types that reflect major environmental characteristics. The resulting five major climate types are defined as follows:

(i) tropical rain climates $(\mathrm{A})$ : the mean tempera- 


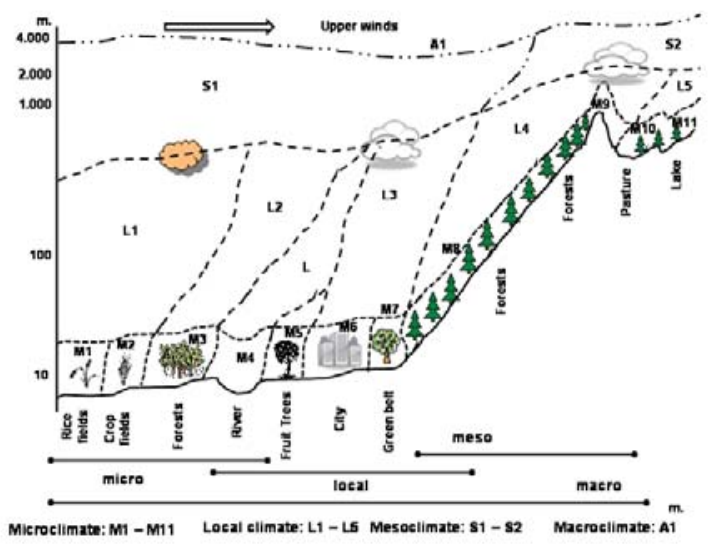

Fig. 3. Climatic phenomena at micro, local, meso and macro scale (adapted from Yoshino, 1978).

ture of the coldest month exceeds $+18.0^{\circ} \mathrm{C}$;

(ii) arid climates (B): on the basis of the average annual precipitation sum $\mathrm{R}(\mathrm{cm})$ and the annual mean temperature $\mathrm{T}\left({ }^{\circ} \mathrm{C}\right)$;

(iii) temperate rain climates $(\mathrm{C})$ : the mean temperature of the coldest month is between $-3.0^{\circ} \mathrm{C}$ and $+18.0^{\circ} \mathrm{C}$;

(iv) boreal forest and snow climates (D): the mean temperature of the warmest month exceeds $+10.0^{\circ} \mathrm{C}$ and the mean temperature of the coldest month is below $-3.0^{\circ} \mathrm{C}$; and

(v) cold snow climates (E): the mean temperature of the warmest month is below $+10.0^{\circ} \mathrm{C}$.

Based on recent data sets from the Climatic Research Unit (CRU) of the University of East Anglia, UK, and the Global Precipitation Climatology Centre (GPCC) at the German Weather Service, a new Köppen-Geiger world climate classification for the second half of the 20th century has been defined and is presented in Figure 4 (Kottek et al., 2006). According to this, the main zonal climates include:

(i) latitudinal climates - temperature regimes determined by the location of a place north or south of the equator, e.g. polar climate, temperate climate, sub-tropical climate and tropical climate;

(ii) regional climates - patterns of weather that affect a significant geographical area and that can be identified on account of special features which distinguish them from other climate patterns. The main factors determining regional climate are: (i) differences in temperature caused by distance from the equator and seasonal changes in the angle of the sun's rays as Earth rotates; (ii) planetary distribution of land and sea masses; and (iii) the worldwide system of winds, called the general circulation, which arises as a results of the temperature difference between the equator and the poles. Examples of regional climates are maritime climate, continental climate, monsoon climate, Mediterranean climate, Sahelian climate and desert climate.

\section{Climate variability and change}

Climate variability refers to the temporal variations of the atmosphere-ocean system around a mean state. Typically, this term is used for timescales longer than those associated with synoptic weather events (i.e. months to millennia and longer). The term "natural climate variability" is used to identify climate variations that are not attributable to or influenced by any activity related to humans.

Climate change refers to a statistically significant variation in either the mean state of the climate or in its variability, persisting for an extended period (typically decades or longer), and may result from:

(i) natural factors, such as changes in the Sun's intensity or slow changes in Earth's orbit around the Sun;

(ii) natural processes within the climate system (e.g. changes in the ocean circulation); and

(iii) human activities that change the atmosphere's composition (e.g. through burning fossil fuels) and the land surface (e.g. deforestation, reforestation, urbanization, desertification, etc.).

The causes of climate variations can be divided into those due to external forcing and those that occur because of factors internal to the climate system (i.e. the natural internal variability). In fact, in the absence of external forcing, the heat content of the system would stay constant. However, heat may redistribute itself geographically, between different reservoirs (e.g. 
between the oceans and the atmosphere), or between different thermodynamic states (such as water vapor to liquid water to ice). Such redistributions occur continuously on timescales from seconds to millennia. External forcing effects can be divided into natural influences and human influences (Wigley, 2003).

\section{Global warming}

Earth's atmosphere functions like the glass walls of a greenhouse, trapping sufficient solar energy to keep the global average temperature at about $15^{\circ} \mathrm{C}$ instead of $450^{\circ} \mathrm{C}$ like on Venus' surface or $-53^{\circ} \mathrm{C}$ on Mars. The atmospheric gases, mainly water vapour $\left(\mathrm{H}_{2} \mathrm{O}\right)$, carbon dioxide $\left(\mathrm{CO}_{2}\right)$, methane $\left(\mathrm{CH}_{4}\right)$, and nitrous oxide $\left(\mathrm{N}_{2} \mathrm{O}\right)$, called "greenhouse gases" (GHGs) function as global insulators and the trapped heat energy makes Earth warmer than it would be without these gases. In fact, without an atmosphere, Earth's surface temperature would be far below freezing and life on Earth would not be possible. On the other hand, an increase in atmospheric GHGs could result in increased trapped heat and rising global temperatures. However, human activities are making the blanket "thicker" as the natural levels of these gases are being increased by emissions of $\mathrm{CO}_{2}$ from the burning of coal, oil, and natural gas, by additional $\mathrm{CH}_{4}$ and $\mathrm{N}_{2} \mathrm{O}$ produced by farming activities and changes in land use, and by several long-lived industrial gases that do not occur naturally. These changes are evolving at an unprecedented speed and the result is known as the "enhanced greenhouse effect", i.e. a warming of the Earth's surface and its lower atmosphere.

By increasing the amount of GHGs in the atmosphere through the burning of fossil fuels (coal, oil, gas) and deforestation, Earth's natural greenhouse effect has been enhanced. This means that more of the Sun's radiation is now trapped in the Earth's atmosphere, and the additional heat in the atmosphere causes mean air and sea surface temperatures to rise all over the globe. This phenomenon is termed "global warming". Therefore, global warming is an average increase in the temperature of the atmosphere near the Earth's surface and in the troposphere, which can contribute to changes in global climate

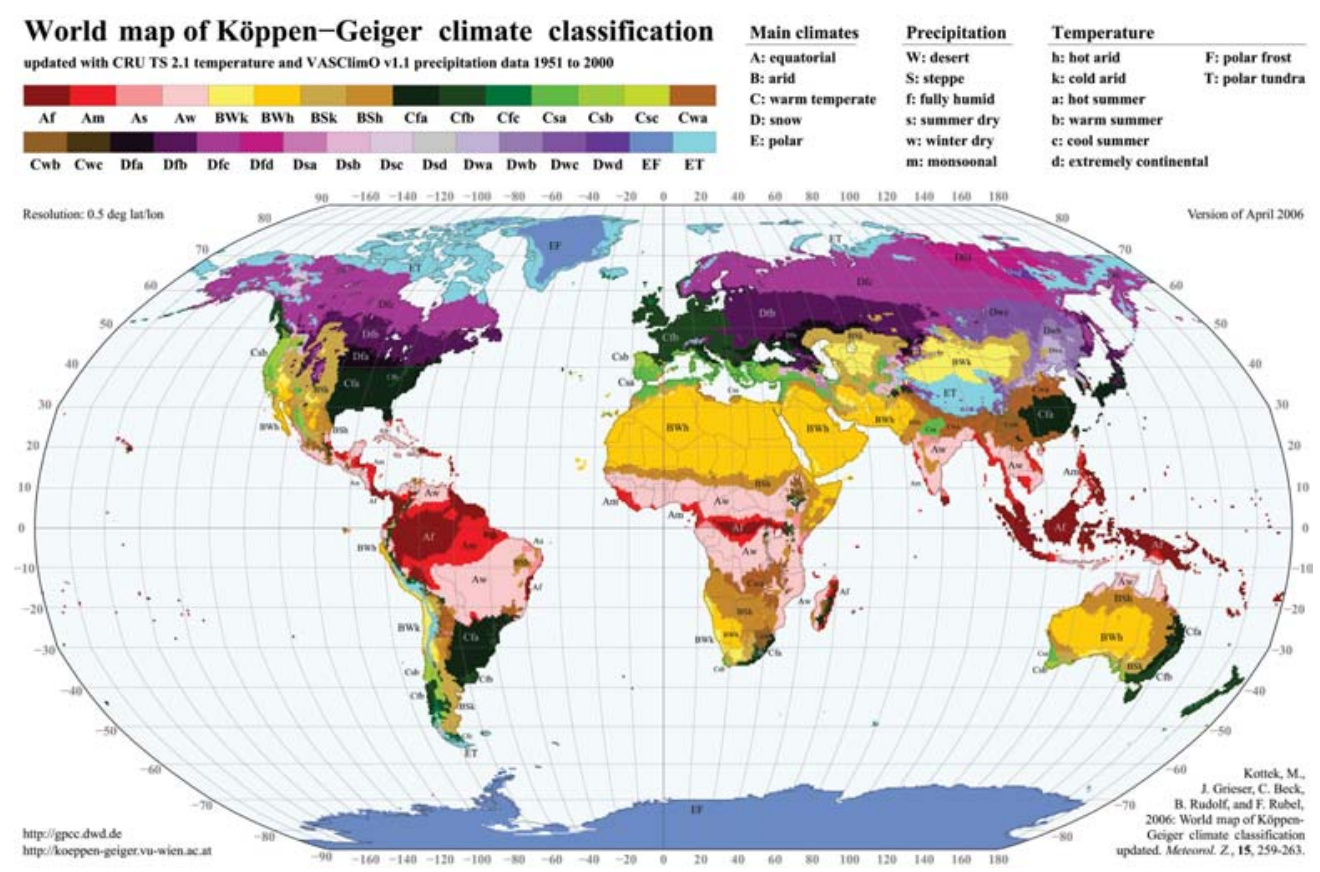

Fig. 4. The Köppen-Geiger world climate classification (source: Kottek et al., 2006). 
patterns. Global warming can occur from a variety of causes, both natural and human induced.

The United Nations Framework Convention on Climate Change (UNFCCC), in its Article 1, defines "climate change" as: "a change of climate which is attributed directly or indirectly to human activity that alters the composition of the global atmosphere and which is in addition to natural climate variability observed over comparable time periods" (UNFCCC, 1992). The UNFCCC thus makes a distinction between "climate change" attributable to human activities altering the atmospheric composition, and "climate variability" attributable to natural causes.

\section{Responses to climate change}

There are two main approaches that can be taken in response to climate change:

(i) mitigating climate change by reducing emissions and sequestering carbon, i.e. to act on the causes; and

(ii) adapting to climate change by improving the quality of information and its use, providing insurance against climate change risk, adopting known good practices to strengthen the resilience of vulnerable livelihood systems, and finding new institutional and technological solutions, i.e. to act on the effects.

Mitigation of climate change involves actions to reduce GHGs emissions and to sequester or store carbon in the short-term and make development choices that will lead to low emissions in the longterm. Adaptation to climate change involves adjustments in natural or human systems and behaviour that reduce the risks posed by climate change to people's existence. While mitigation and adaptation are conceptually distinct, they are in practice interdependent and both are equally important from a human health perspective.

Climate is an environmental resource (solar energy, rainfall, heat, etc.) as well as an environmental hazard and it varies over different time scales. Human populations have developed ways to cope with the variability, but climate change is modifying expected and known variability patterns, sometimes to the extent that people are confronted with situations that they are not well equipped to handle. Adaptation is thus an immediate concern, with mostly immediate benefits but it is highly location-specific.

\section{The "human health dimension"}

Weather and climate variability can affect human health through direct and indirect effects: the former involve physical impacts that cause physiologic stress (e.g. temperature) or injury (e.g. storms, floods). Indirect effects, such as impact on food supplies and outbreaks of vector-borne diseases, may operate through different pathways involving multiple variables. The distinction never exists in reality as even strong direct effects of climatic factors on the organism are modified through the impact of other environmental factors affected by climatic factors. However, it must be considered that factors other than the climate are influenced by humans and they affect the environment and ultimately human health. They are the contaminants of human activities released into the air, the water and the soil, including alteration of vegetation and other land surfaces (Balbus and Wilson, 2000). Concerning global climate change, there are five possible pathways through which climate change can impact human health: (i) temperature-related morbidity and mortality; (ii) health effects associated with air pollution; (iii) effects of extreme weather events (and drought) on population health; (iv) water- and food-borne disease; and (v) vector-borne disease (Henry, 2002). The main pathways by which global climate change can affect population health are schematized in Figure 5 where mitigation mainly refers to the reduction of GHG emissions while adaptation concerns interventions to reduce adverse health effects.

Most observations of the relation between climate and health are based on climate variability as on a day-to-day, month-to-month, and even yearto-year basis, climatic conditions have a great impact more than they do on a decade-to-decade 
basis, and even more than is predicted with enhanced greenhouse effect. In assessing the health impacts of long-term climate change, a distinction must be made between health effects that are influenced by short-term climate variability and health effects that may be influenced by long-term changes (Balbus and Wilson, 2000).

\section{Global climate assessment}

The first major global assessment of climate change science in six years (IPCC, 2007b) has concluded that changes in the atmosphere, the oceans and glaciers and ice caps show unequivocally that the world is warming. In its report, the Intergovernmental Panel on Climate Change (IPCC) stated with "very high confidence" that the increase in atmospheric concentrations of GHGs since 1750, $70 \%$ of which has taken place between 1970 and 2004 , is the result of human activities. In 2005 they exceed by far the natural range over the last 650,000 years and, concerning human health, the
IPCC assessment concluded that climate change currently contributes to the global burden of disease and premature deaths with "very high confidence". Emerging evidence of climate change effects on human health shows that climate change has:

(i) altered the distribution of some infectious disease vectors (medium confidence);

(ii) altered the seasonal distribution of some allergenic pollen species (high confidence); and

(iii) increased heatwave-related deaths (medium confidence).

There is clear evidence that climate change plays a prominent role in the spatial and temporal distribution of several diseases like malaria, dengue, tickborne diseases, cholera and other diarrhoeal ones as well as in the seasonal distribution and concentrations of some allergenic pollen species. The projected health impacts of climate change are predominately negative - most severe impacts affecting lowincome countries - and also positive including lower climate suitability for vector-borne diseases in some regions. The assessment put the emphasis on the

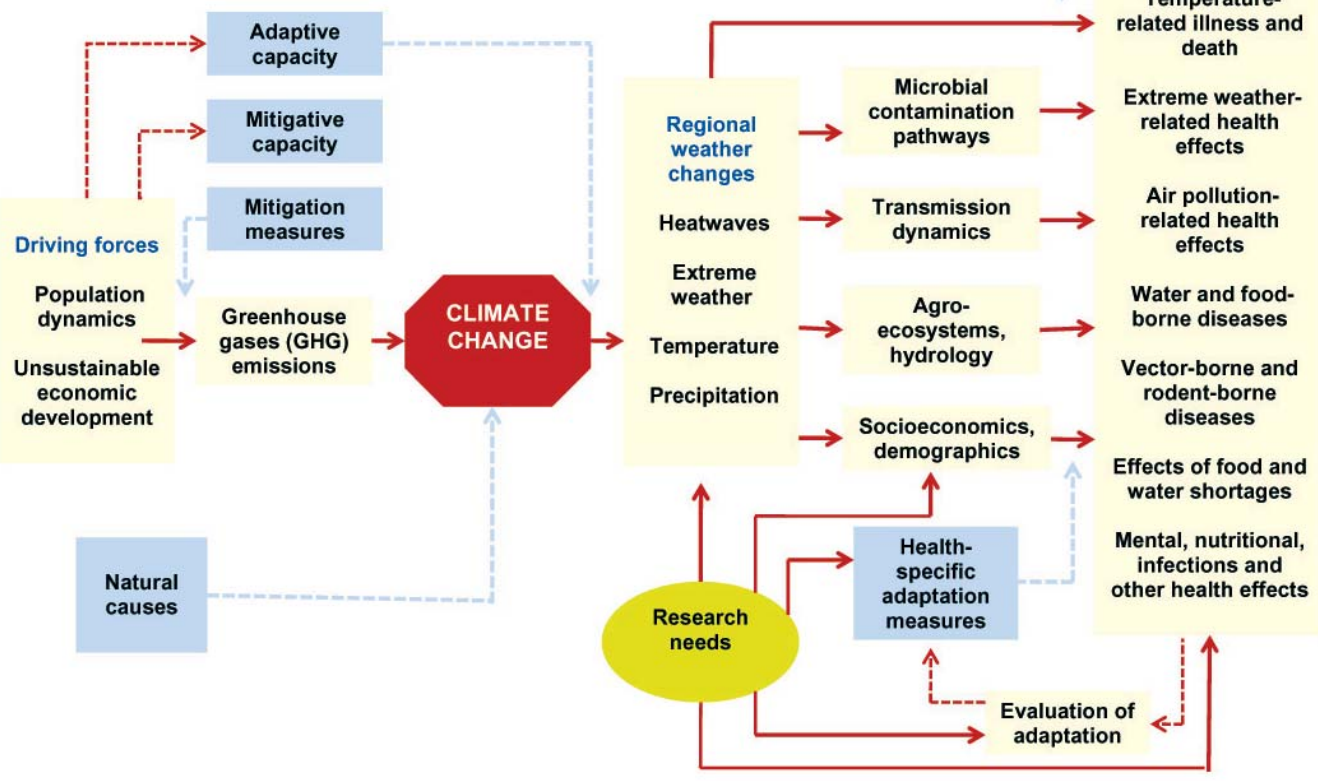

Fig. 5. Schematic summary of main pathways by which climate change affects human health (source: McMichael et al., 2003). 
need to develop and implement adaptation strategies, policies and measures at different levels and scales.

\section{Climate change, food security and human health}

The food security situation of a household is determined by four factors: food availability, access to food, stability of supply and accessibility, to which can be added the degree to which food is nutritious, safe and contributing to an active and healthy life (FAO, 1996). Climate change is a real threat to development and puts additional pressure on already limited resources and these phenomena are most likely to affect developing countries, which have the least capacity to meet these new challenges. Poverty and hunger are largely interlinked since poverty is recognized both as the cause and the outcome of hunger. Poor people are likely to have less access to healthy, nutritious food, which results in a poor health status and lower labour productivity. These two factors then contribute to maintaining the vicious cycle of poverty and malnutrition. An additional effect of climate change is the changing patterns of animal diseases and their direct link to human health and well-being. Temperature changes, as well as increased air pollution, can enhance human disease patterns, as does the spread of transboundary animal diseases with their relationship to pathogens potentially dangerous to humans. Avian $\mathrm{flu}^{2}$ is the most recent example. Food security and human health linkages, combined with the most likely effects of climate change, clearly show the globalization aspect and the interconnection between developed and developing countries. Any contribution made to safeguard the protection of the envi-

\footnotetext{
2 Highly pathogenic avian influenza (HPAI).

3 Synoptic station: a station at which meteorological observations are made for the purposes of synoptic analysis. The observations are made at the main synoptic times of 00.00, 06.00, 12.00, 18.00 UTC and normally at the intermediate synoptic hours of 03.00, 09.00, 15.00, 21.00 UTC and are entered into a coded format for further dissemination. From: http://amsglossary.allenpress.com/glossary
}

ronment in developing countries will have a direct and a positive effect in the developed countries.

\section{Meteorological and climatic measurements in rela- tion to buman health}

Detection and measurement of the effects of climate change on human health are necessary to provide evidence on which to base policy options at national and international levels relating to adaptation and mitigation measures. Clear evidence of health effects, and accurate measurements of their size, can come only from globally high-quality and comprehensive observations. Without such baseline data it is not possible to develop the products needed by policy makers and other stakeholders. Such undertakings can only be achieved through an international coordinating mechanism and through the use of common methodologies and standards.

Meteorological factors influence health processes either directly or indirectly. Temperature, relative humidity, rainfall and wind-speed are perhaps the most important and can all be predicted (with a greater or lesser degree of certainty) to affect the future climate. A network of meteorological stations covers all countries in the world but, in practice, there are difficulties in obtaining reliable series of daily measurements of these variables for all representative sites due to poor density of these stations particularly in the developing countries where climate effects on human health is of particularly great concern.

As an example, Africa's conventional synoptic stations $^{3}$, fundamental for climate modelling and adaptation strategies, are thin on the ground. For example, there are just over 1,150 World Weather Watch stations in Africa giving a density of 1 per 26,000 $\mathrm{km}^{2}$, eight times lower than the WMO minimum recommended level. The density of meteorological stations has a very large variation and it can be assumed that, on average, the density varies from none to about eight rainfall stations per $1,000 \mathrm{~km}^{2}$ and from none to one synoptic station per $1,000 \mathrm{~km}^{2}$. In many developing countries, the density has also a negative trend which is underscored 
by Figure 6 showing a decrease in the numbers of operational stations by-year and by-country in the Greater Horn of Africa from 1960 to 2005 in almost all countries of the region. Meanwhile little of Africa's - and other world regions - historical meteorological and climate data is being used to further refine climate forecasting and assist in better adaptation and coping strategies. This is because much of the historical data remain paper-based and are inaccessible to scientists who need digital data to feed global circulation models.

Meteorological and climate data are essential in monitoring health impacts such as the evaluation of the dynamics of vector-borne diseases based on climate-health modelling and climatic datasets need to be at a resolution representing in an adequate way the linkages between climate and human health. Climate data at high spatial resolution can be produced by statistical downscaling using historical observations but the method is limited by the lack of historical meteorological data at local level. The kind of needs concerning the climatic and health data is shown in Table 1.

In order to estimate missing data for a specific region, measurements made at the stations can be interpolated using different methods to derive estimates up to the entire globe at different spatial resolutions (Bernardi et al., 2006). Proxy measurements of meteorological variables such as temperature, rainfall and wind speed are also made by sensors installed on board of geostationary ${ }^{4}$ and polar orbiting 5 satellites providing a global coverage. Concerning rainfall, a technique for estimation of precipitation over Africa has been developed and implemented by NOAA's (U.S. National Oceanic and Atmospheric Administration) Climate Prediction Center to augment the rainfall data available from the relatively sparse observational network of rainfall stations over the continent (Xie and Arkin, 1997). The final product is a rainfall estimation (RFE) digital imagery and is regularly distributed by the U.S. Agency for International Development (USAID) Famine Early Warning Systems Network (FEWS NET), an information sys-

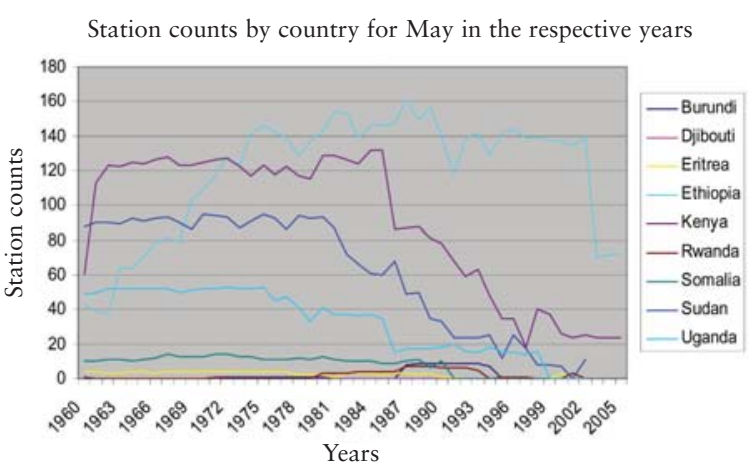

Fig. 6. By-year, by-country counts of meteorological stations in the Greater Horn of Africa.

tem designed to identify problems in the food supply system that potentially lead to famine or other food-insecure conditions in sub-Saharan Africa, Afghanistan, Central America and Haiti. The RFE method utilizes METEOSAT geostationary satellite infrared data, Global tele-communication System (GTS) ${ }^{6}$ rainfall stations reports for the computation of daily estimates of accumulated rainfall (in $\mathrm{mm}$ ) at a spatial resolution of about $8 \mathrm{~km}$. The method still requires an improvement of the accuracy of RFE, especially in areas with low real-time gauge densities and complex topography and substantial improvements to RFE accuracy can be obtained with additional rainfall data (Funk, 2006).

One important application of RFE is the monitoring of current rainfall anomalies in zones at malaria epidemic risk. Rainfall is one of the major factors influencing malaria transmission in semi-arid and desert-fringe areas of Africa. Epidemics may occur

\footnotetext{
4 Geostationary satellite: a satellite in a west-to-east orbit at an altitude of $35,786 \mathrm{~km}$ above the equator. At this altitude, it circles the axis of the Earth once every 24 hours, making its speed in orbit synchronous with the earth's rotation. From: http://amsglossary.allenpress.com/glossary

5 Polar-orbiting satellite: a satellite with an orbit that lies in a plane passing through the center of the Earth. From: http://amsglossary. allenpress.com/glossary

6 Global Tele-communications System (GTS) is the globally integrated communications that provides for the collection and distribution of meteorological data within the World Weather Watch of the WMO. From: http://amsglossary.allenpress.com/glossary
} 
Table 1. Needs concerning the climatic and health data for interdisciplinary study (adapted from Rose et al., 2001).

\begin{tabular}{ll}
\hline Climate & Health \\
\hline Increased temporal resolution & Long-term surveillance \\
Increased spatial resolution & Better reporting \\
Local topography & Access to historical data \\
More input from "user" groups (ecology and health) & Conversion of data to electronic formats \\
Integration of forecasts & Demographic and socio-economic information \\
Forecasting sequential climate events & \\
\hline
\end{tabular}

after excessive rains, usually with a lag time of several weeks during which mosquito vector populations and malaria infections gradually increase. The maps based on RFE provide a simple indicator of changes in malaria risk in marginal transmission areas based solely on rainfall, showing differences above and below expected levels ${ }^{7}$.

Concerning the environmental satellites, they can certainly have a great capability to deliver global data on the climate system so that they are particularly useful to study climate change and to validate and assess the quality of climate models through the collection of long-term and consistent Earth observations data sets. These sensors allow the uses of remote sensing technology beyond vector-borne diseases such as cholera and schistosomiasis and the mapping of human settlements at risk (Beck et al., 2000). However, a review of the use of remote sensing in health over the last 25 years of their applications has showed the poor quality of data sources and processing used, revealing limitations between theory and practical implementations in health, and especially epidemiology (Herbreteau et al., 2006). Most studies are based on the low-resolution images chosen, because they are free of charge or available at a low cost and not for their relevance regarding the objectives of the study. Considering that the choice of scales in mapping health is a fundamental issue to understand diseases dynamics, being limited to the resolutions of the image is obviously a major weakness which is rarely mentioned. As long as the access to high spatial resolution images at low cost will be not avail-

\footnotetext{
7 FEWS-NET Africa Data Dissemination Service, http://earlywarning.usgs.gov/adds/index.php
}

able, the use of remote sensing will be very limited in health studies. It must also be considered that, while remote sensing imagery provides an important support in identifying trends - in time - and patterns - in space - of main climatic variables, the level of the accuracy of their measurements is directly linked to the calibration with ground data.

\section{Rate of change and abrupt changes}

With regard to adaptation to the impacts of global warming on human health, one of the most important factors is the rate at which climate variables (e.g. temperature, rainfall, relative humidity, and cloudiness) and GHGs can change. The IPCC assessment report projected an increase in global average surface temperature increase of between $1.8^{\circ} \mathrm{C}$ and $6.4^{\circ} \mathrm{C}$ for the end of the 21 st century (2090-2099) relative to the period 1980-1999. The projections consider that these increases will be gradual in the future so that the effects of global warming can potentially be manageable for most countries. However, a hypothesis also suggests the possibility that this global warming could lead to a relatively abrupt change in a shorter period of time, perhaps a decade, where the climate system either at the global or at the regional level crosses a threshold and switches to a new state. Abrupt changes could be caused by the collapse of the thermohaline circulation $^{8}$ or by the additional release of GHGs from

\footnotetext{
8 The thermohaline circulation (THC) is the part of the large-scale ocean circulation driven by the fluxes of heat and freshwater at the ocean surface. THC is also called the ocean conveyor belt, the great ocean conveyer, the global conveyor belt, or, the meridional overturning circulation (MOC). From: http://amsglossary.allenpress.com/glossary
} 
permafrost and the oceans or by a rapid rise in sea level that would result from disintegration of the West Antarctic Ice Sheet (Arnell et al., 2005). Paleoclimatic evidence suggests that altered climatic patterns could last for as much as a century, as they did when the ocean conveyor collapsed 8,200 years ago, or, at the extreme, could last as long as 1,000 years as they did during the Younger Dryas, which began about 12,700 years ago (Schwartz and Randall, 2003). However, the IPCC assessment report stated that it is "very likely" that the meridional overturning circulation (MOC) of the Atlantic Ocean will slow down during the 21 st century and that it is "very unlikely" that there will be a large abrupt transition of the MOC during the 21st century (IPCC, 2007c).

A continuous and accurate monitoring of climatic elements is fundamental to detect if the rates over time are incrementally changing so that it is possible to define health-specific adaptation measures and put them in practice. If, however, the rates of change are too fast in order to implement adaptation options, then it will not be possible to implement suitable responses in order to get a minimal impact on human health.

\section{Essential climate variables}

Adequate high-quality observations of climate and climate-related variables are essential if mitigation- and adaptation-related measures are to be based on deliberate planning leading to better policies. Consistent observations acquired over extended periods make possible an understanding of the frequency of extreme events as well as average climate conditions. The Global Climate Observing System (GCOS), established in 1992 and coordinated by WMO (1992), focuses on satellite and in situ climate observations in the atmospheric, oceanic and terrestrial domain. Ocean climate observing systems are planned jointly with the Global Ocean Observing System (GOOS), while terrestrial climate observing systems are planned jointly with the Global Terrestrial Observing System (GTOS).
Changes influence climate-responsive diseases, in particular parasitic diseases relying on intermediate hosts and vectors such as for example schistosomiasis and malaria, and contribute to the emergence of new diseases. This could impact both the food chain and people's physiological capacity to obtain necessary nutrients from the foods consumed. For the assessment of the impact on food security by the climate, FAO considers a comprehensive definition of climate change that encompasses changes in longterm averages for all the essential climate variables (ECVs) to be the most useful. For many of these variables the observational record is too short to be able to state with certainty whether recent changes represent true shifts in the long-term means (climate change), or whether they are simply anomalies around a stable mean (climate variability).

Although climate per se relates only to the varying states of the Earth's atmosphere, other parts of the climate system also have a significant role in forming the climate through their interactions with the atmosphere. A list of variables essential for monitoring changes in the climate system has been developed by GCOS. The list includes atmospheric, oceanic and terrestrial phenomena, and covers all the spheres of the climate system (Table 2). Specifically the reporting system on ECVs provides information to:

(i) characterize the state of the global climate system and its variability;

(ii) monitor the forcing of the climate system, including both natural and anthropogenic contributions;

(iii) support the attribution of the causes of climate change;

(iv) support the prediction of global climate change;

(v) enable projection of global climate change information down to regional and local scales; and

(vi) enable characterization of extreme events important in impact assessment and adaptation, and to the assessment of risk and vulnerability.

The mission of GCOS is to ensure the availability and quality of the atmospheric, oceanic and terrestrial data needed for climate system monitoring, 
research, prediction, impact assessment and response actions. Such data obtained both in situ and from space are required by a wide variety of users for:

(i) climate system monitoring;

(ii) climate change detection and attribution;

(iii) research to improve understanding, modeling and prediction of the climate system;

(iv) operational climate prediction on seasonal-tointer-annual timescales; (v) assessment of the impacts of, and vulnerability and adaptation to, natural climate variability and human-induced climate change;

(vi) applications and services for sustainable economic development; and

(vii) requirements of the UNFCCC and other international conventions and agreements.

GCOS coordinates the data collection from the world climate observing stations (Fig. 7). At the pres-

Table 2. Essential climate variables (ECVs) for GCOS, GOOS and GTOS.

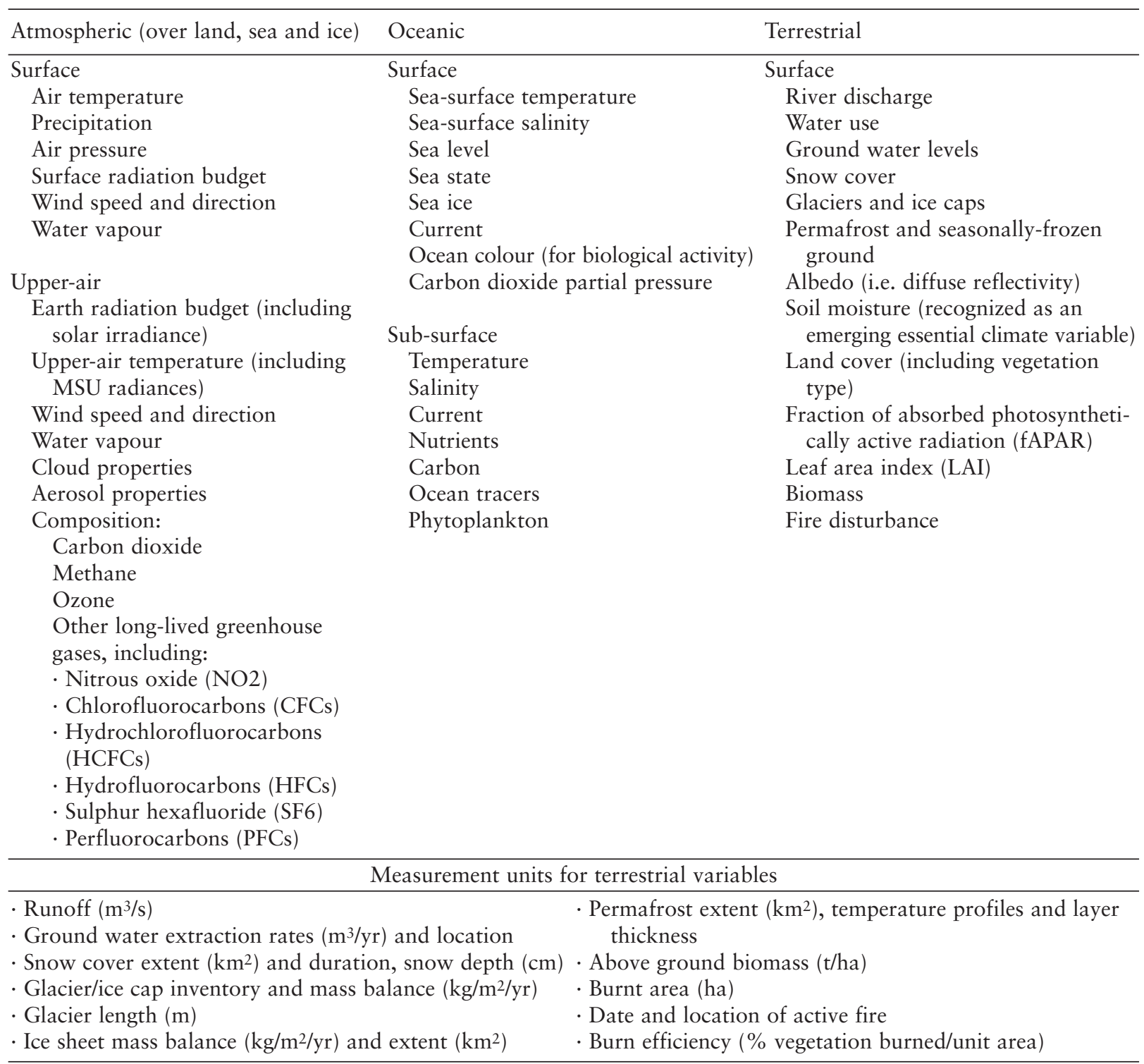




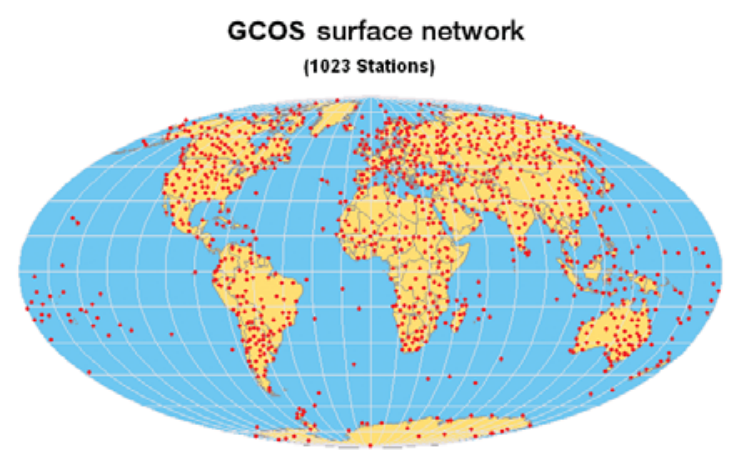

GCOS Secretariat, 1 February 2008

Fig. 7. GCOS surface network (source: GCOS Secretariat, 2007).

ent time, in many countries neither the quality nor quantity of observations needed by global, regional and local area models is adequate to support and verify climate models so as to allow the reliable projections needed for adaptation purposes. In order to meet adaptation needs, models will need to be improved and observation networks and data use will need to be strengthened, especially in vulnerable areas.

\section{Conclusions}

A basic requirement for both developed and developing countries is to define the policies to mitigate and to adapt to global climate change, data and information at all scales. However, as compared to mitigation, adaptation is an immediate concern for developing countries and for small islands states, where the reduction of the emissions from GHGs is

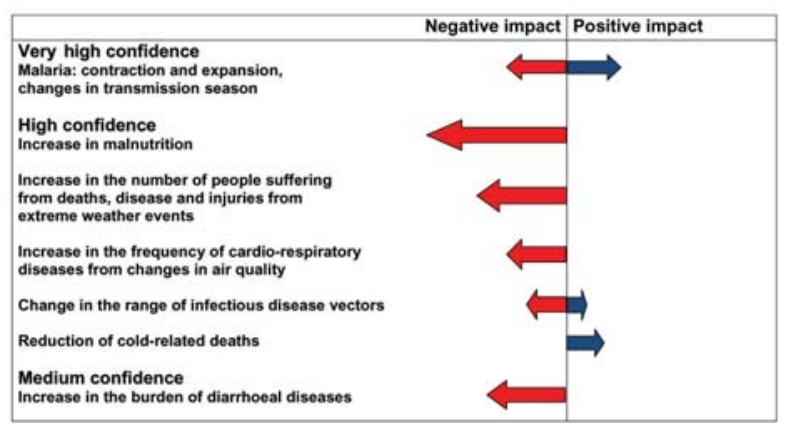

Fig. 8. Direction and magnitude of change of selected health impacts of climate change (source: IPCC, 2007b). not among their priorities. An important characteristic is that adaptation is highly location-specific and, in many developing countries, the required ground data to assess the impacts of climate change on human health are not available. Climate data at high spatial resolution can be derived by various downscaling methods using historical and real-time meteorological observations but, particularly in developing countries, the outputs are limited by the lack of ground data at local level which is confirmed by the negative trend in the number of operational stations observed in some regions. The use of remote sensing imagery has been very limited in health studies due to the lack of high-resolution spatial images at low cost.

This present situation has been clearly indicated in the IPCC climate assessment report on human health which underlines the existing gap on detailed information on trends in climate, health and environment in low-income countries. Based on the existing data it is very difficult for these countries to make their vulnerability assessment and to define best strategies, policies and measures at all levels to adapt to the impact of climate change. Projected health impacts could be largely underestimated in low-income countries due also to the large uncertainties linked to the rate and intensity of future global climate change. Various key areas have been defined by the IPCC report to address the major challenges for a better understanding of the linkages between climate change and human health (Fig. 8). However, given the actual circumstances in low-income countries, unless a strong effort to improve the meteorological observations network - including large urban areas - is put in place, health monitoring systems cannot play their key role in protecting human health from climate change effects.

\section{References}

Arnell N, Tompkins E, Adger N, Delaney K, 2005. Vulnerability to abrupt climate change in Europe. Tyndall Centre Technical Report 34. Tyndall Centre for Climate 
Change Research, UK.

Balbus JM, Wilson M, 2000. Human health and global climate change. A review of potential impacts in the United States. PEW Center on Global Climate Change, Arlington, USA.

Beck LR, Lobitz BM, Wood BL, 2000. Remote sensing and human health: new sensors and new opportunities. Emerg Infect Dis 6, 217-226.

Bernardi M, Gommes R, Grieser J, 2006. Downscaling climate information for local disease mapping. Parassitologia 48, 69-72.

FAO, 1996. World Food Summit. Technical background documents. Rome, Italy.

FAO, 2007. Climate Change and Food Security: a framework document. Interdepartmentak Working Group on Climate Change. FAO, Rome, Italy.

Funk C, 2006. Overview of FEWS-NET rainfall validation/enhancement activities. Climate Hazard Group, Geography Research Unit, University of California, Santa Barbara, USA.

Henry C, 2002. Impacts of climate change on human health. Discussion paper C3. Climate Change Central. Calgary, Canada.

Herbreteau V, Demoraes F, Hugot JP, Kittayapong P, Salem G, Souris M, Gonzalez JP, 2006. Perspectives on applied spatial analysis to animal health. A case of rodents in Thailand. Ann NY Acad Sci 1081, 17-29.

IPCC, 2001a. Climate Change 2001. Working Group I: the physical science basis. Summary for policy makers working group I to the Intergovernmental Panel on Climate Change. Third Assessment Report (TAR).

IPCC, 2007a. Climate Change 2007: synthesis report glossary. Fourth Assessment Report (AR4).

IPCC, 2007b. Climate Change 2007: climate change impacts, adaptation and vulnerability. Summary for policy makers working group II to the Intergovernmental Panel on Climate Change. Fourth Assessment Report (AR4).
IPCC, 2007c. Climate Change 2007: the physical science basis. Summary for policy makers working group I to the Intergovernmental Panel on Climate Change. Fourth Assessment Report (AR4).

Köppen W, 1936. Das Geographische System der Klimate. Handbuch der Klimatologie, Bd. 1, Teil C.

Kottek M, Grieser J, Beck C, Rudolf B, Rubel F, 2006. World map of the Köppen-Geiger climate classification updated. Meteorol Z 15, 259-263. http://koeppen-geiger.vuwien.ac.at/

McMichael AJ, Campbell-Lendrum DH, Corvalán CF, Ebi KL, Githeko AK, Scheraga JD, Woodward A, 2003. Climate change and human health. Risks and responses. WHO. Geneva, Switzerland.

Rose JB, Anwar H, Lipp E K, 2001. Health, climate and infectious diseases. A global perspective. Report of the American Academy of Microbiology.

Schwartz P, Randall D, 2003. An abrupt climate change scenario and its implications for United States National Security.

UNFCCC, 1992. United Nations Framework Convention on Climate Change. Bonn, Germany.

WHO, 2006. Constitution of the World Health Organization. Basic Documents, Forty-fifth edition, Supplement. Geneva, Switzerland.

Wigley TML, 2003. The science of climate change. Global and U.S. Perspectives. The pew center on global climate change, Arlington, USA.

WMO, 1992. International Meteorological Vocabulary, $2^{\text {nd }}$ edition. Publication No.182. Geneva, Switzerland.

Xie P, Arkin PA, 1997. A 17-year monthly analysis based on gauge observations, satellite estimates, and numerical model outputs. Bull Am Met Soc 78, 2539-2558.

Yoshino MM, 1978. Climate in a small area: an introduction to local meteorology. University Tokyo Press, Tokyo, Japan. 